\title{
Compressive behavior of concrete cylinder fully and partially confined by carbon fibre- reinforced polymer (CFRP)
}

\begin{abstract}
Partial CFRP-confinement has been used as an option beside full CFRP-confinement for strengthening structural elements. However, the sufficiency of partial CFRP-confinement has always been uncertain. Therefore, this paper presents 24 specimen cylinders $(300 \mathrm{~mm} \times 150 \mathrm{~mm})$ strengthened with partial CFRP-confinement horizontal and helicoidal strip. The results from both modes of partial CFRP confinement with strip spacing of 60, 40, and $20 \mathrm{~mm}$ were compared with full confinement and unconfined specimens. Partial horizontal CFRP strip confinement at $20 \mathrm{~mm}$ strip spacing yielded a reasonable load capacity $(80.56 \mathrm{MPa})$ at $71 \%$ strength enhancement. Therefore, partial CFRP confinement with a horizontal strip is proven sufficient. Theoretical predictions and the test results are being compared as well in evaluating the accuracy of existing FRP-confined concrete model.
\end{abstract}

Keyword: Fibre-reinforced polymer; Partial confined; CFRP confinement; Stress-strain model 